\title{
Contributing Factors of the Choice of Poultry Waste Management Practices: Evidence from Nigeria
}

\section{Gbigbi Theophilus Miebi}

Department of Agricultural Economics and Extension, Delta State University Asaba Campus, Asaba, PMB 95074, Asaba, Nigeria

\begin{abstract}
The research was conducted to evaluate the choice of management practices for poultry wastes in Delta State. A multistage sampling procedure was used to obtain data from 133 respondents. A well structured questionnaire was used for the study. Data were analyzed using descriptive statistics, cost and return analysis and binary logit. Results showed that $70.9 \%$ were male with an average age of 44 years. About $73.0 \%$ were married with $99.0 \%$ acquiring formal education. The mean household size was 5 persons with mean farming experience of 6 years. Burying and burning were the primary waste management practices employed. The binary logit result indicates that age ( $p<0.05)$, educational level $(p<0.05)$, household size $(p<0.05)$, type of bird $(p<0.05)$ and poultry housing method $(p<0.05)$ were positively significant while marital status $(p<0.05)$ was negatively significant among the factors affecting the choice of poultry waste management practices by the farmers in the study area. The major challenges in managing poultry waste were inadequate information, weather condition, lack of convenient dumping space and unavailability of litter material.
\end{abstract}

Keywords—choice, poultry, waste, management practices, farmers.

\section{INTRODUCTION}

Poultry is the raising of domesticated birds such as chickens, ducks, turkey, and geese which are of economic and nutritional benefit to man by providing him meat and eggs for food. Poultry is one of the most developed animal industries in Nigeria. To this end, Bolan et al (2010) reiterated that the poultry sector is one of the world's biggest and fastest expanding agro-industries. Alongside the increase in poultry patronage and activities, the business is faced with numerous environmental problems. The challenge is aggravated by large-scale accumulation of wastes which poses disposal and pollution problems Ekenma (2015). Orhervata and Omoyakhi (2008) gave an estimated daily waste generation of poultry farms to be between $0.09 \mathrm{~kg}$ and $0.18 \mathrm{~kg}$, depending on the farm size. According to Williams (2010), poultry production result in hatchery waste, manure, litter and mortality on the farm. In furtherance, Moreki and Keaikitse (2013) noted that the poultry sector produce large quantities of waste which comprises of solid waste and waste water. The solid waste comprises of bedding materials, excreta, feed feathers, hatchery waste, shells, sludge, abattoir waster (Offals, blood, condemned carcasses and feathers) and mortality. The waste water result from washing and disinfecting of poultry house and abattoirs.

There are several ways poultry waste can be managed and disposed which are burial, rending, compositing, fertilizer, feed for livestock. Other methods of disposal for poultry waste include the use of poultry waste for heavy metalpolluted water treatment as well as for conversion to power (Draper and Tomlinson 2012. It has been observed that reusing poultry waste can be beneficial and economical, if managed properly by farmers.

According to Idowu and Otuniaya (2002), despite the widespread importance and uses, less than $10 \%$ of poultry waste is recycled through feed in Nigeria. Previous studies shows the same pattern in most African countries for handling poultry wastes (Ayodeji et al , 2011; Adeoye et al. 2014). The predominant waste management practices in Nigeria and Botswan are dumping on adjacent wastelands 
or spills into pits and nearby rivers. Although some farmers also used composting (Ayodeji et al., 2011; Moreki and Keaikitse, 2013).

Farmers 'choice of disposal techniques depends on the environment, the location, the nature of the poultry housing and the number of birds (Charles 2008) and the socioeconomic characteristics of the farmers (Idowu and Otuniaya 2002), and Adedayo 2012; Ojewale 2014).

According to Vide (2012), there had been no conscious effort made to clearly understand the management practices of poultry waste for urban agriculture; problems associated with its acquisition, handling, organization, seasonal variations and farmers perception as well as their implications on yield. This concern has brought the need to focus attention on the choice and practices used for managing poultry waste in Delta State. Understanding the drivers of poultry waste management and utilization techniques especially as its affect crop yield and revenue generation among farmers, could pave way for improving poultry waste activities for urban agriculture and consequently increase income.

A report by Moore, Miles and Burn (2006) revealed that most poultry farms stored the waste for about 4-6 weeks on their farms before they heap them up and burn, flush them into drain or dispose them of with other domestic refuse. He further stated that about $50 \%$ of the poultry farmer spread the waste on nearby land, $40 \%$ of poultry farmer burns the waste after sun drying while only 5\% compost the waste. The inappropriate and carelessness of this important aspect of poultry waste management in the farms, can lead to disease outbreak.

Poultry farmers' attempts to remove poultry waste often entail additional maintenance costs, and if left unmanaged, such residues will possibly pose an environmental threat to farmers (Rashid et al., 2010). Poultry wastes have failed to be properly managed in Nigeria because of a number of factors including ignorance, lack of technical knowledge , high management costs, lack of adequate technology, and lack of policies (Idowu and Otuniaya, 2002; Adedayo, 2012; Adeoye et al., 2014; McAllister, 2015).

In Nigeria, the current poultry waste disposal methods are neither economical nor environmentally friendly (Adeoye et al, 2014; Kalu et al 2016). Animal dung is also likely to induce soil and air flow if the effluences if the agronomic uptake for the crop obtained is less than the deposits of nutrients (Cofie and Drechsel, 2005; Charles, 2008). And the choice of disposal method differs from one farmer to another in their location (Charles, 2008).

Thus, environmental, human health, potential earnings and quality of life issues for both poultry farmers and people living near and far from poultry production locations are crucial to waste management's long-term growth and sustainability in poultry production.

Poultry manure represent a valuable resource that if properly managed can replace large amount of chemical fertilizers. The first goal of any waste management system is to maximize the economic benefit from the waste resource and uphold an acceptable environmental standard. Studies on determinants of choice of poultry waste management are in short supply, especially in Delta State. The specific objectives are to: determine the socio economic profile of poultry farmers, ascertain the methods of waste management practices adopted by poultry farmers, determine the factors affecting the choice of poultry waste management practices by farmers and ascertain the challenges of poultry waste management practices.

\section{MATERIALS AND METHOD}

\section{Study Area}

This research was conducted in Oshimili North Local Government Area of Delta State, Nigeria. The study area has a population of 143,361 people (National Population Commission, 2006).. It has GPS coordinates of $6^{\circ} 19^{\prime} 21.83^{\prime \prime}$ $\mathrm{N}$ and $6^{\circ} 38^{\prime} 40.02^{\prime \prime} \mathrm{E}$ (Live satellite map, 2019). The study area has a mean temperature of $29^{\circ} \mathrm{C}$ with annual rainfall ranging from $1,500 \mathrm{~mm}$ to $2,200 \mathrm{~mm}$ per annum (Ukwuaba and Inoni, 2012). Rainy season is between April and October. The major occupations of the people are farming, fishing and trading. The major livestock reared include poultry, piggery and goat while major crops produced are yam, melon, cassava, maize. Rural poultry is prominent in the study area.

\section{Sampling Technique/ Data Collection}

A two stage sampling procedure was used to handpick 135 poultry chicken farmers in the area of study. The first stage involved purposive selection of poultry farms from 9 communities based on prevalent of good number of poultry farmers involved and the second stage involved a random sampling method of 15 respondents from each community to give 135 poultry farmers selected from the list obtained from the ministry of agriculture and natural resources Delta 
State. The sampling frame comprised the list of all registered poultry farmers obtained from the ministry of agriculture and natural resources Delta State. However, only 133 questionnaires were retrieved for the study. The survey was conducted using a pretested were structured questionnaire.

\section{Data Analysis}

Data was analyzed using descriptive statistics and inferential statistics such as binary logit.

\section{Model Specification}

\section{Binary model}

Binary model was used to analyze the determinants of the choice of poultry waste management practices. Let us assume that the response variable $\mathrm{Y}^{*}$ captures the true status of the farmer either adopt waste management practices or not, the regression equation can be estimated as follows;

$\mathrm{P}(\mathrm{Y}=1)=\underline{\underline{\mathrm{B}_{2}}}$

$$
1+\mathrm{e}^{\mathrm{\beta} x}
$$

$\mathrm{P}(\mathrm{Y}=0) \quad=\quad 1-\frac{\mathrm{e}^{\beta \mathrm{x}}}{(2)} \quad=\quad \underline{1}$
(2)

$$
1+\mathrm{e}^{\beta \mathrm{x}} 1+\mathrm{e}^{\mathrm{\beta} \mathrm{x}}
$$

The empirical specification for examining the explanatory variables is,

$\mathrm{Yi}=\mathrm{bo}+\mathrm{b}_{1} \mathrm{x}_{1}+\mathrm{b}_{2} \mathrm{x}_{2}+\mathrm{b}_{3} \mathrm{x}_{3}+\mathrm{b}_{4} \mathrm{x}_{4}+\mathrm{b}_{5} \mathrm{x}_{5}+\mathrm{b}_{6} \mathrm{x}_{6}+\mathrm{b}_{7} \mathrm{x}_{7}+$ $\mathrm{b}_{8} \mathrm{x}_{8}+\mathrm{b}_{9} \mathrm{x}_{9}+\mathrm{b}_{10} \mathrm{x}_{10}+\mathrm{b}_{11} \mathrm{x}_{11}+\mathrm{et}$

\section{(3)}

$\mathrm{Y}_{\mathrm{i}}=$ Dependent variable indicating the farmers use of waste management practices. $\mathrm{Y}_{\mathrm{I}}^{*}$ is not observable and is a latent variable. $\mathrm{Y}$ is observed as a dummy variable that takes the value of 1 if $Y^{*}>0$ and takes the value 0 otherwise. $\mathrm{X}$ are the various household level socioeconomic factors that determine farmers choice of waste management practices.

$\mathrm{b}_{0}=$ Constant

$\mathrm{X}_{1}=$ Gender

$\mathrm{X}_{2}=$ Age

$\mathrm{X}_{3}=$ Marital status

$\mathrm{X}_{4}=$ Educational level

$\mathrm{X}_{5}=$ Household size

$\mathrm{X}_{6}=$ Occupation

$\mathrm{X}_{7}=$ Farming experience

$\mathrm{X}_{8}=$ Size of farm
$\mathrm{X}_{9}=$ Type of birds

$\mathrm{X}_{10}=$ Type of poultry housing method

$\mathrm{X}_{11}=$ Method of disposal

et $=$ Stochastic error term

\section{RESULTS AND DISCUSSION}

\section{Socio-economic profile of the respondents}

\section{Sex Categorization of Respondents}

Table 1 shows that out of the surveyed 133 poultry farmers, $70.7 \%$ were male while $29.3 \%$ were female. This implies that the poultry farms in the study area were dominated by males. Male dominance may possibly be because of the rigours required to take care of the birds to maintain. The evidence is supported by Olumayowa and Otunaiya (2011) claims that poultry production is possibly masculine because its activities require physical strength that men can provide alone.

\section{Age Distribution of Respondents}

Most of the farmers (45.0\%) fall within the age range of 2741 years, $45.0 \%$ of the respondents falls within the age bracket of (27-41) with a mean of 44 years. This implies that they are young and very energetic to carry out tedious work associated with poultry waste management. This is in line with the findings of Olumayowa and Otunaiya (2011) that poultry farmers are mostly middle-aged citizens.

\section{Marital Status of Respondents}

The finding shows that most of the respondents $72.9 \%$ were married. This suggests that marriage is part of most culture and as such every marriage age individuals take to marriage with a view to raising family and sustain their generation genealogically.

Educational Level of Respondents The results shows that $0.8 \%$ had non-formal education, $1.5 \%$ had primary education, $27.1 \%$ had secondary education and $70.7 \%$ had tertiary education. This implies that most of the respondent had formal education which could possibly help them to innovate a good poultry management practices.

\section{Household Size Distribution of Respondents}

The distribution of respondents according to their individual household sizes showed that $57.9 \%$ had between 4-6 persons per household, with a mean of 5 persons. This indicates labour availability to carry out waste management operations easily. The size of households affects the 
possible number of labour readily available for individual poultry farmer, according to Olumayowa and Otunaiya (2011).

\section{Occupation Distribution of Respondents}

The result of the distribution of respondents showed that $68.4 \%$ of respondents had farming as their primary occupation, while the remaining $31.6 \%$ of the respondents were involved in other business as their secondary source of income. This implies that the respondents also engaged in other income generating activities. Akanni and Benson (2014) support this outcome.

\section{Farming Experience of the Respondents}

The results showed that $(68.4 \%)$ of the respondents had been in poultry farming between 1 and 6 years, with a mean of 6 years. This implies that the respondents were relatively new in poultry management. Knowledge on management is key to poultry production which is gained through years of experience by poultry farmers. This result agrees with the findings of Aromolaran et al. (2013) in his study on challenges of small poultry farms in layer production in Oyo State.

\section{Size of the farm}

In addition, the Table 1 shows that $50.4 \%$ of the respondent had small farm, $25.6 \%$ had medium farm size and $24.1 \%$ had large farm size. This implies that majority of the respondents in the study area operate scale poultry farm.

Farmers are therefore expected to be able to handle poultry wastes because of their small stock size. Olumayowa and Otunaiya (2011) support this finding that $78 \%$ of farmers raised less than five thousand birds.

Table 1: Socio-economic profile of respondents $(n=133)$

\begin{tabular}{llll}
\hline Variable & Frequency & Percentage \% & Mean \\
\hline Gender & 94 & 70.7 & \\
Male & 39 & 29.3 & \\
Female & & & 44 years \\
Age & 60 & 45.0 & \\
$27-41$ & 58 & 43.6 & \\
$42-56$ & 15 & 11.3 & \\
$57-71$ & & & \\
Marital status & 22 & 16.5 & \\
Single & 97 & 72.9 & \\
Married & 6 & 4.5 & \\
Divorced & 8 & 6.0 & \\
Widow & & & \\
Educational level & 1 & 0.8 & \\
No formal Education & 2 & 1.5 & \\
Primary & 36 & 27.1 & \\
Secondary & 94 & 70.7 & \\
Tertiary & $\mathbf{1 3 3}$ & 37.9 & \\
Total & & & \\
Household size & 37 & & \\
1-3 & & & \\
4-6 & & & \\
\hline
\end{tabular}




\begin{tabular}{lll}
\hline $7-9$ & 17 & 12.8 \\
$10-12$ & 2 & 1.5 \\
Occupation & 91 & \\
Farmer & 12 & 68.4 \\
Politician & 23 & 9.0 \\
Civil servant & 7 & 17.3 \\
Trader & & 5.3 \\
Experience & 91 & \\
$1-6$ & 37 & 68.4 \\
$7-12$ & 4 & 27.8 \\
$13-18$ & 1 & 3 \\
$19-24$ & & 0.8 \\
Size of farm & 67 & \\
Small & 34 & 50.4 \\
Medium & 32 & 25.6 \\
Large & & \\
\hline
\end{tabular}

\section{Waste management practices employed by the farmers}

Table 2 portrays types poultry waste management practices employed by the poultry farmers. The outcome discloses that $63.2 \%$ of the respondents adopted burying of wastes management system. Poultry farmers take on this method due to the offensive smell fascinating diversity of pests, rodents as their habitat and also it could also result to environmental pollution. However, $27.8 \%$ of the farmers preferred burning of dead birds. The residual poultry farmers $6.0 \%$ and $3.0 \%$ adopted composting and flushing approaches respectively. This finding is congruent with the study by Zeeuw (2000) that exposed poultry wastes are a breeding ground for a number of pests, rodents and also a major source of pollution in the environment. Dead birds represent a large share of poultry waste.

Table 2: Waste management practices employed by the farmers $(n=133)$

\begin{tabular}{|c|c|c|}
\hline $\begin{array}{ll}\text { Waste } & \text { mgt } \\
\text { practices } & \end{array}$ & Frequency & Percentage \\
\hline Burying & 84 & 63.2 \\
\hline Burning & 37 & 27.8 \\
\hline Composing & 8 & 6.0 \\
\hline Flushing & 4 & 3.0 \\
\hline
\end{tabular}

ISSN: 2456-1878

\section{Determinants of choice of poultry waste management practices}

The result indicate that age, educational level, marital status, household size, poultry housing method and type of bird produced are significant at 5\% probability level while gender, farming experience, occupation, size of the farm and method of disposing poultry waste are not significant in determining whether the farmers will use any form of poultry waste management practice.

The result showed that age (0.44) was positively signed and significant at 5\% and this implies that increase in the age of poultry farmers led to a corresponding increase in the choice of poultry waste management practices. The coefficient for educational level (0.950) was positively signed and significant at 5\%. This implies that increase in educational level will lead to an increase in the choice of waste management. When the farmers are educated, they have better knowledge and reasons why waste should be managed. The coefficient for marital status (-0.666) was negatively signed and significant at $5 \%$. This implies that increase in marital status will lead to a decrease in the choice of poultry waste management. The coefficient for household size $(0.368)$ was positively signed and significant at $5 \%$. This implies that increased in household size will 
result to an increase in the choice of waste management practice. The coefficient for type of birds' produce (1.447) was positively signed and significant at 5\%. This implies that if the birds generate high quality of waste on daily or weekly basis, it encourage the farmer to adopt waste management practice. Birds like layers produce more manure and odour and this can be a factor affecting the choice of waste management practice. The coefficient for poultry housing method $(0.730)$ was positively significant at $5 \%$.This positively affect the choice of poultry waste management because the type of housing method encourages a farmer to manage waste just like in Battery cage housing method where managing of waste is very simple and easy to carry out.

The coefficient for disposal method (0.437) was positively significant at $5 \%$.This positively affect the choice of poultry waste management because the type of waste disposal method a farmer is conversant with will bring about willingness to adopt poultry waste management practices.

Table 3: Binary logit regression on determinants of choice of poultry waste management

\begin{tabular}{lllll}
\hline Variables & B & SE & wald & Sig (p-value) \\
\hline gender & 0.419 & 0.452 & 0.859 & 0.354 \\
age & 0.440 & 0.137 & 2.631 & $0.005 * *$ \\
marital status & -0.666 & 0.273 & 3.181 & $0.054 * *$ \\
educational level & 0.950 & 0.415 & 5.238 & $0.022 * *$ \\
household size & 0.368 & 0.130 & 0.615 & $0.033 * *$ \\
Occupation & -0.106 & 0.186 & 0.323 & 0.570 \\
farming experience & -0.045 & 0.069 & 0.420 & 0.517 \\
size of farm & -0.086 & 0.249 & 0.120 & 0.729 \\
type of bird & 1.447 & 0.560 & 6.671 & $0.010 * *$ \\
poultry housing method & 0.730 & 0.358 & 4.158 & $0.041 * *$ \\
method of disposal & 0.437 & 0.136 & 2.335 & $0.002^{* *}$ \\
Constant & -9.387 & 2.737 & 11.764 & $0.001 * * *$ \\
\hline
\end{tabular}

$* * *$ significant at $1 \%, * *$ significant at $5 \%, *$ significant at $10 \%$.

\section{Challenges of Poultry Waste Management}

Table 4 showed that out of the 133 respondent, $36.8 \%$ (49) respondents said inadequate information about waste management practice, $24.8 \%$ (33) said weather condition is a major challenge in managing poultry waste, $9.0 \%$ (12) said lack of convenient dumping space, $6.8 \%$ (9) said there were no buyers, $9.8 \%$ (13) said unavailability of litter material is a challenge in managing waste, $4.5 \%$ (6) said shortage of labour, $4.5 \%$ (6) said odour is a challenge and $3.8 \%$ (5) said flies and mosquito. This indicates that most of the respondent in the study area are faced with the major challenge of weather condition.

Table 4: Challenges of Poultry Waste Management

\begin{tabular}{lll}
\hline Variable & Frequency & Percentage \\
\hline $\begin{array}{l}\text { Inadequate } \\
\text { information }\end{array}$ & 49 & 36.8 \\
Weather condition & 33 & 24.8 \\
$\begin{array}{l}\text { Lack of convenient } \\
\text { dumping space }\end{array}$ & 12 & 9.0 \\
Lack of buyers & 9 & \\
Unavailability of litter & 13 & 6.8 \\
material & & 9.8 \\
Shortage of labour & 6 & \\
Odour & 6 & 4.5 \\
Flies and mosquito & 5 & 4.5 \\
Total & $\mathbf{1 3 3}$ & 3.8 \\
\hline
\end{tabular}




\section{CONCLUSION AND RECOMMENDATIONS}

The most important waste management practices employed by farmers were burying and burning. The relevant determinants of the choice of poultry waste management practices in the study area has been properly identified and documented. This shows that age, educational level, household size, type of bird and poultry housing method positively contributed to waste management choice while marital status contributed negatively to the choice of waste management at 5\% probability level respectively. The major constraints are inadequate information, weather condition, unavailability of litter material and lack of convenient dumping space. It is therefore recommended that the government and other bodies should provide incentives to the poultry farmers for construction of litter shed.

\section{REFERENCES}

[1] Adedayo, V. (2012). Poultry Waste Management Techniques in Urban Agriculture and its Implications: A Case of Metropolitan Lagos, Nigeria, Asian Journal of Agricultural Sciences, 4(4): 258-263.

[2] Adeoye, P. A., Hasfalina1, C. M.., Amin, M. S. M. Thamer, A. M. and. Akinbile, C. O (2014). Environmental Implication of Poultry Waste Generation and Management Techniques in Minna, Semi-arid Region of Nigeria, Annual Research \& Review in Biology, 4(10):1669-1681.

[3] Akanni, K.A. and Benson, O.B. (2014). Poultry Wastes Management Strategies and Environmental Implications on Human Health in Ogun State of Nigeria. Advances in Economics and Business, 2(4): 164-171, 201.

[4] Ayodeji, O. O., Oluwatoyin G. T., and Akinsoyinu, A. O. (2011). An overview of poultry and livestock waste management practices in Ogun State, Nigeria, Journal of Food, Agriculture \& Environment, 9 (3\&4): 643 - 645.

[5] Aromolaran, A.K., Ademiluyi, I.O and Itebu, O.J. (2013). Challenges of small poultry farms in layer production in Ibadan Oyo State Nigeria. Global Journal of Science Frontier Research Agriculture and Veterinary Science 13(2):31-50.

[6] Bolan, N.S; Szogi, A.A; Chuasavathi, T; Seshadri, B; Rothrock, M.J and Panneerselvam, P. (2010). Uses and management of poultry litter. World's poultry science Journal, 66(3):21-32.

[7] Charles, M.W. (2008). Poultry Waste Management in developing Countries, Utilization of Poultry Waste. Food and Agriculture Organization of the United Nations, Poultry Development Review. 3-9.
[8] Cofie, O.A.B. and Drechsel, P. (2005). Recycling of Urban Organic Waste in Urban Agriculture. In: Veenhuizen, V., (Ed.), Urban Agriculture for Green and Producing Cities. IIRR and ETC Urban Agriculture, 209-226.

[9] Draper, K. and Tomlinson, T. (2012). Poultry litter Biocharaus perspective. International Biochar initiative New Orleans; McGraw Hills Inc.

[10] Ekenma, K. (2015). Poultry litter/manure management practices in intensively managed poultry farms in Port Harcourt. IOSR Journal for Agriculture and Veterinary Science, 8(3):53-58.

[11] Idowu, A.O. and Otuniaya A.O. (2002). Analysis of Poultry Waste Management Techniques in Ikorodu Area of Lagos State, Nigerian Southwest Journal of agricultural Economics and Extension, 4(2):37-46.

[12] Kalu, E., Ajaruonye, A. N. and Okwara, N. (2016). Waste Management Practices in Selected Poultry Farms in Umuahia, Abia State, Journal of Veterinary Advances, 6(9):1310-1316.

[13] Live satellite map (2019). https://latitude.to/map/ng/nigeria/regions/delta-state/oshimilinorth.

[14] McAllister, J. (2015). Factors Influencing Solid-Waste Management in the Developing World, All Graduate Plan B and other Reports 528, Utah State University, Logan, Utah, 20-75.

[15] Moore, P, Miles, D and Burn, R. (2009). Reducing ammonia, emission from poultry litter with alum. USDA Agric. Res. Service Bull: 1082-1091.

[16] Moreki, J.C and Keaikitse, T. (2013). Poultry waste management practices in selected poultry operations around Gaborone, Botswana. International Journal of current microbiological Applied Science, 2(7):240-248.

[17] Ojewale, O.S. (2014). Intra-urban Analysis of Domestic Solid Waste Disposal Methods in a Sub-Sahara African City, Journal of Waste Management, 2:2-5.

[18] Olumayowa O. and Otunaiya O.A. (2011): Profit Efficiency and Waste Management in Poultry Farming: The Case of Egba Division, Ogun State, Nigeria, International Journal of Poultry Science, 10 (2): 137-142.

[19] Orheruata, A.M and Omoyakhi, J.M. (2008). Livestock Environment interaction: Issues and options in Nigeria. Journal of Applied Scientific Environment Management 12(2):129-133.

[20] Rashid R., Malik A.B.M. and Khan M.S (2010), Biological Treatment of Organic Waste for Poultry Farm in Hot Climate International Journal of Sustainable Water \& Environmental Systems Vol. 1 (1):11-14.

[21] Ukwuaba S and Inoni E.O. (2012). Resource-Use Efficiency in Small-Holder Broiler Production in Oshimili North Local Government Area, Delta State. International Journal of Poultry Science 11 (11): 700-705. 
International Journal of Environment, Agriculture and Biotechnology, 5(3)

May-Jun, 2020 / Available: https://ijeab.com/

[22] Vide A. (2012). Poultry waste management techniques in Urban Agriculture and its implications: A case metropolitan Lagos, Nigeria. Asian Journal of Agricultural Sciences, 4(4):258-263.

[23] Williams C.M. (2010). Poultry waste management in developing countries: food and Agriculture organization perspective. Poultry management review, 23(4):1-4.

[24] Zeeuw H, (2000). Urban and Peri-Urban Agriculture, health and environment. Discussion Paper for FAO-ETC/RUAF Electronic Conference' Urban and Peri-urban Agriculture on the policy Agenda" Online Document. 